\title{
Quality Control of Ink Bottles in Efforts to Control Defect Products in Candi Plastik Home Industry
}

\author{
Tri Ilma Sari and Moses Laksono Singgih \\ Department of Technology Management, Institut Teknologi Sepuluh Nopember, Surabaya \\ e-mail:triilmasari@gmail.com
}

\begin{abstract}
Quality is one of the most important things in terms of competition between companies. Products that are not of quality will be rejected. Many home industries lose competitiveness in terms of quality, it could be due to inaccurate machining. This causes a lot of product defects. A dozen years this home industry was established, but has not yet met the minimum target defect target of products set by consumers. Quite a lot of products have to be replaced and reworked. So we need a tool to control quality and detect the causes of product defects and then repair the cause. Seven tools are the seven basic tools that are able to solve the quality problems faced by production. Failure Mode Effect Analysis (FMEA) is a tool to detect the causes of production failures. The application of these two tools is expected to be able to control quality, meet the minimum specifications of consumers, detect the causes and correct the causes, increase productivity, reduce losses, and increase consumer confidence. The results of this study are seven tools and FMEA able to control product defects, the percentage of product defects produced by $22.5 \%$, the cause of product defects is caused by 4 factors namely machinery, humans, methods, and raw materials. Whereas based on FMEA analysis, the main cause of product defects is the machine, and proposed control settings of the machine.
\end{abstract}

Keywords-Defective Products, FMEA, Product Quality, Seven Tools.

\section{INTRODUCTION}

$\mathrm{Q}$ UALITY is one of the most important things in terms of competition between companies. Home industries that are unable to compete in quality will be unable to compete. This home industry has experienced quite complex problems, namely producing substantial product defects in a single production. It is estimated that the product defect is around $50 \%$ in the past 9 years. The main problem faced by the home industry is located on the defect product produced. Many methods are used to discuss quality with their respective characteristics. Quality control methods include map controls, seven tools, quality management, and so on. The method of analyzing the cause is FMEA, cause and effect diagrams, and so on [1]. Quality Control Using the Statistical Quality Control (SQC) Method is able to Minimize Failed Products, The results obtained from this journal are the number of failed products still within control, and the cause of product failure is humans [2], the use of FMEA is able to identify failures in the production process [3], [4].

Quality of product is the ability of a product to perform its functions, it includes the product's overall durability, reliability, precision, ease of operation and repair, and other valued attributes [5]. The dimensions of product quality consist of eight dimensions, namely: performance, reliability, features, conformance to specification, durability, serviceability, esthetic, and perceived quality [6].

Plastic bottles are inexpensive, durable and lightweight materials, which are very easy to make for use in various products. Critical quality that needs to be reviewed from a plastic bottle can be seen from two sides, namely based on consumer users and based on environmental governments (post use of bottles). Plastic if viewed based on post-use bottles, which must be analyzed is the composition of the manufacture of bottles which aims to facilitate in how to treat the waste. There are four categories of recycling, namely: primary, secondary, tertiary, and quarterly [7]-[9]. The critical quality of plastic bottles when viewed based on postuse bottles, which must be analyzed is the composition of the manufacture of bottles that aims to facilitate in how to treat the waste. There are four categories of recycling, namely: primary, secondary, tertiary, and quarterly. When viewed from the consumer's point of view, consumers want the plastic bottles to be safe, where the plastic bottles do not interact with the filling material, making them safe as food containers, medicines, and so on [9]-[11].

Control of product quality can be done by various methods, including the statistical method. Resolution techniques using SQC can help in analyzing, monitoring, controlling, repairing, and managing product and system work processes [12].

Statistical quality control uses 7 (seven) main statistical tools that can be used as tools to control quality, including: check sheets, histograms, control charts, pareto diagrams, cause and effect diagrams, scatter diagrams and process diagrams. Check sheets are aids in data collection making it easier to process data. Histogram is a visualization of defective product data from a check sheet, flowchart is a flow chart that serves to identify the occurrence of problems or bottlenecks in a process (bottleneck), pareto diagrams function to compare each problem as well as cumulative, causal diagrams useful for finding and analyzing factors affecting the cause of failure in product output as well as product quality. Scatter diagram is a diagram that interpolates a factor causing product problems so that it can be seen the correlation of one factor with another factor, as well as the continuity between factors [4]. Control chart is a tool to determine whether a process is in a controlled state or not. 


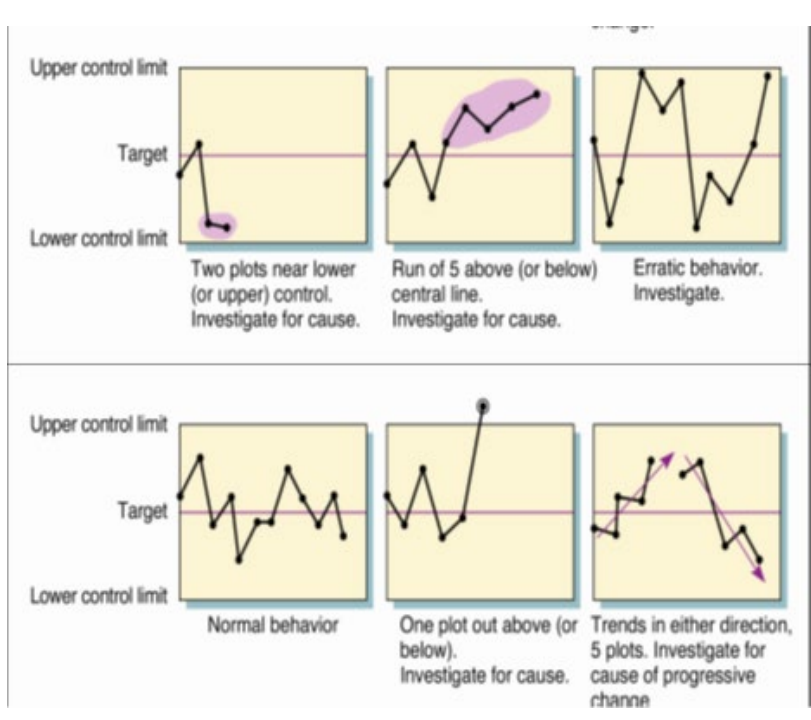

Figure 1. Several Patterns that Cause A Map Out of Control Due to External Factors that can be Traced [13].

Product quality control can be determined by 2 conditions, controlled and uncontrolled conditions. The condition is controlled if all points are within the maximum and minimum limits (control limits), the process is said to be out of control because of external factors that can be traced (assignable causes). The patterns that cause uncontrolled maps shown in Figure 1 [13].

Variable control map is used to control the quality of a product that is variable, can be measured, and can be expressed quantitatively. Variable control map consists of $\mathrm{X}$ map and $\mathrm{R}$ map. The attribute control map is a map used to control the quality of a product that is stated qualitatively (defective product or not). The attribute control map consists of C map, U map, NP map, and P map. Here are the formulas and steps for creating and using the P control map:

a. Calculates the proportion of damage

$p=\frac{n p}{p}$

b. Calculates the center line / Central Line (CL)

$C L=\bar{P}=\sum \frac{n p}{n^{\prime}}$

c. Calculates upper and lower control limits (UCL) and Lower Control Limit (LCL)

$U C L, L C L=\bar{P} \pm 3 \sqrt{\frac{\bar{P}(1-\bar{p})}{n}}$

Note:

$n p:$ Number of products that do not meet the specifications of one sample

$n^{\prime} \quad$ : Amount of data in one sample

$\sum n p$ : Total number of products that do not meet the specifications of all products inspected

$\sum n$ : Total number of products inspected

$\bar{p} \quad$ : Average product mismatch of the total products examined

$n \quad$ : number of all products inspected

Note: If LCL $<0$ then LCL is considered 0

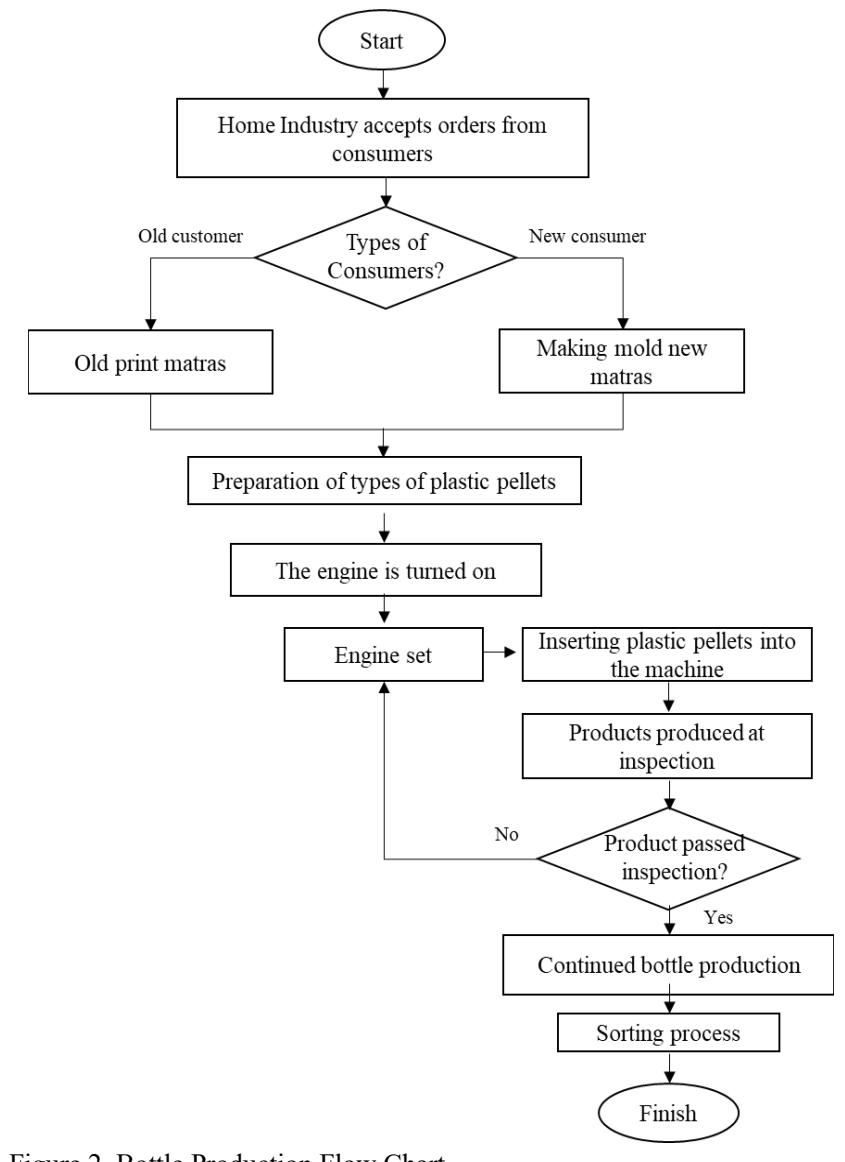

Figure 2. Bottle Production Flow Chart

The data adequacy test aims to get the right analysis. Following is the data adequacy test formula:

$N^{\prime}=\left[\frac{k / s \sqrt{N \sum x^{2}-\left(\sum x\right)^{2}}}{\sum x}\right]^{2}$

Note:

$N \quad$ : The number of observational sample data

$N^{\prime}$ : The amount of theoretical sample data or data that must be done

$k$ : A certain level of confidence, $99 \%$ value $k=3,95 \%$ value $k=2,90 \%$ value $k=1.65$

$s \quad$ : Degree of accuracy

$x$ : Observational data [13].

FMEA is based on cause and effect analysis and will then find out the main causes of product defects. Every possibility that causes failure or defective product is weighted, then it will determine the priority (RPN) of the most influential causes until it has no effect on product output. FMEA can analyze production failures by looking at RPN first, and RPN is influenced by three things namely severity, occurrence, and detection. Severity is also called the level of damage. Occurrence is also called frequency, is a weighting value based on how often the cause of failure occurs during the production process, detection is a step to detect in controlling production failures that may occur. Here is a mathematical formula from RPN:

$R P N=$ Severity $\times$ Occurence $\times$ Detection 
The $1^{\text {st }}$ International Conference on Business and Engineering Management (IConBEM)

February $1^{\text {st }} 2020$, Institut Teknologi Sepuluh Nopember, Surabaya, Indonesia

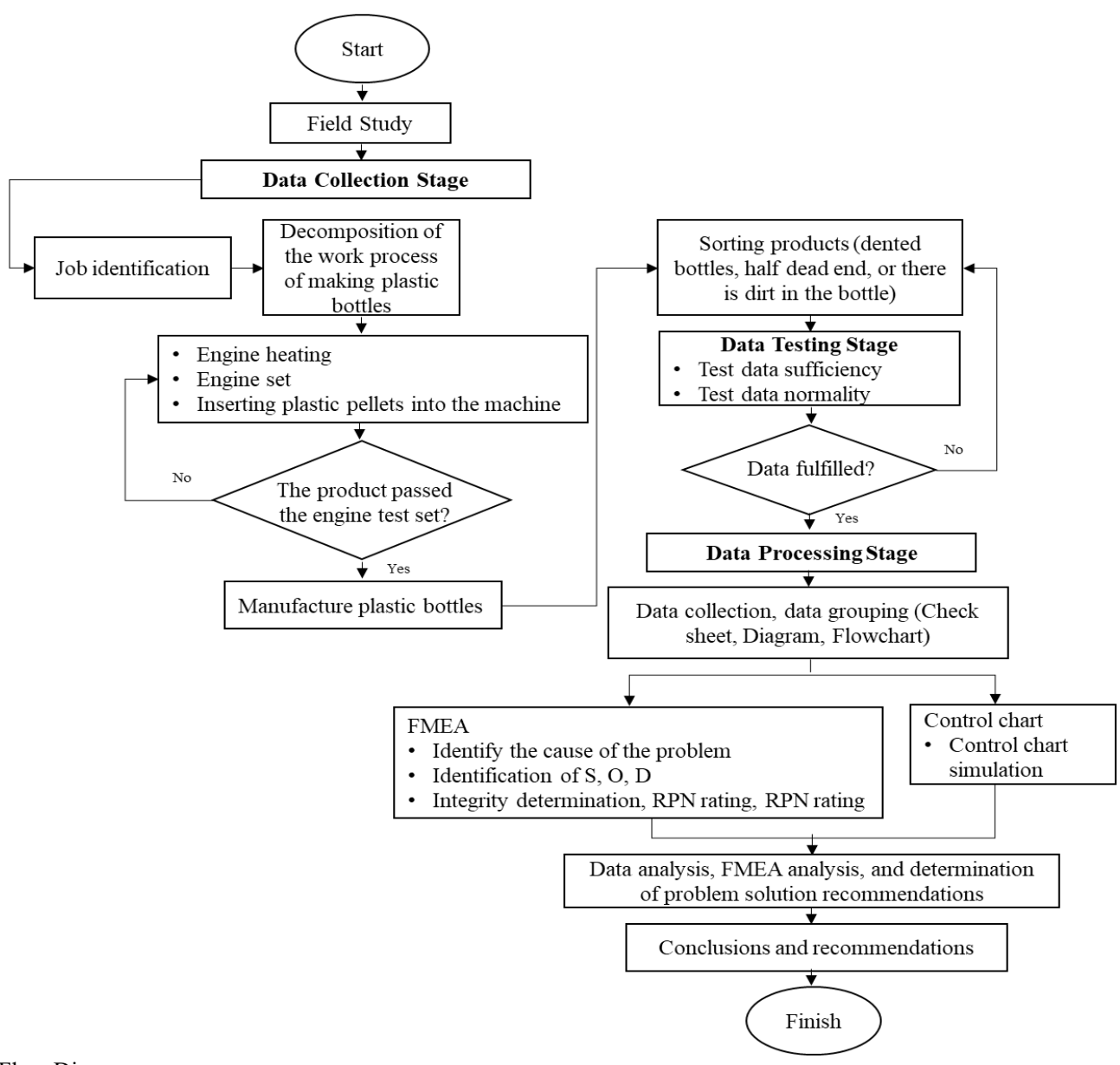

Figure 3. Research Flow Diagram

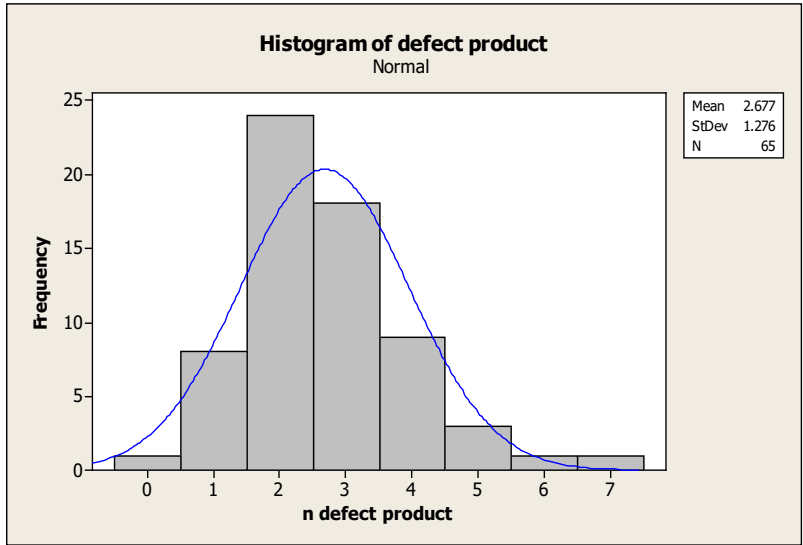

Figure 4. Histogram of Plastic Bottle Defect Products

\section{METHOD}

Product quality control used in this study are seven tools and then analysis of the causes of defective products using FMEA analysis. Defective products studied were three, dented plastic bottles, half holes, and dirty. Data is collected and recorded using a check sheet, then visualization using a histogram, analysis of the flow of the production process using a flowchart, cause analysis using a causal diagram, analysis of defective products using a pareto diagram, analysis of the relationship between causes of defective products using scatter plots, analysis of defective products within the control limits using the control chart, then the last to analyze the most important causes of defects by sorting the risk priority number (RPN) with the FMEA method. The research flowchart can be seen in Figure 2 and Figure 3.

\section{RESULTS AND DISCUSSION}

\section{A. Check sheet and histogram}

This research was conducted according to the flow chart in chapter two. Defective product data recorded using a check sheet shows that the percentage of defective products is $25 \%$. Here is a defective product histogram. Figure 4 shows that the number of defect products that are often found during the sampling process of plastic bottle production is 2 .

\section{B. Flowchart}

From Figure 5 it can be analyzed that a production request starts from a consumer order. For old customers using old matras, but old matras must still be examined and checked whether it can still be used or not, the adjustment in the machine is still good or not. For new customers, matras making can be done, can be done by the home industry or from consumers. However, to maintain product quality results, it is better for consumers to make adjustments from the producers. After the matras is ready, preparation and determination of the number of plastic pellets are needed for production, both the composition of pure and recycled plastic seeds and the readiness of production aids such as water and electricity. Then the engine is turned on for the heater to function, at this stage it takes about 20 minutes to 40 minutes 


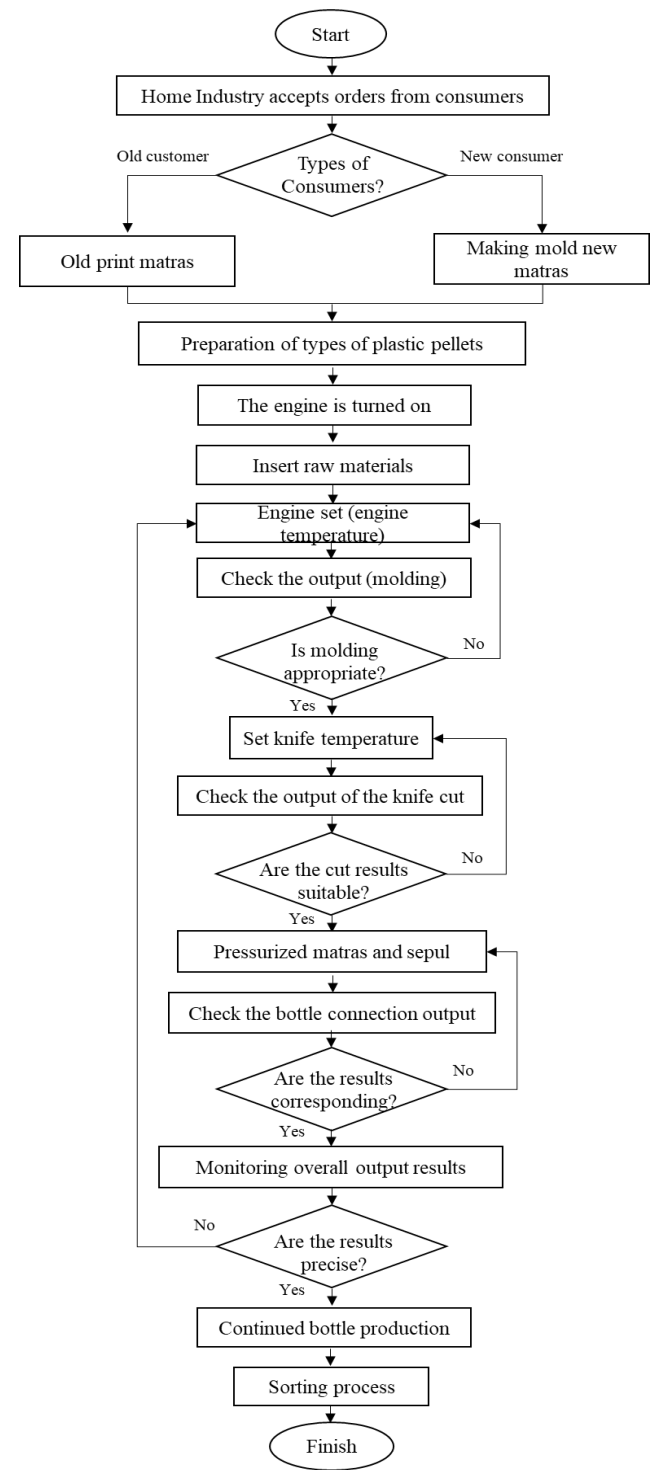

Figure 5. Flow Chart of the Plastic Bottle Production Process

to heat the engine, more precisely for the operational melt of plastic pellets and the overall operation of the machine.

After the machine is ready, pure plastic seeds are inserted into the engine chimney. The plastic pellets enter the engine chimney and then enter the heating chamber so that the pellets melt, the molten pellets come out of the pipe in the form of mold. This mold needs to be checked whether it is good enough for the next process or not. If the engine temperature is too hot, the mold is too soft and makes printing difficult, it can even make dents or other product defects, but if it is too stiff, it is difficult to form. Mold extends to a specified size, then captured by the holder and cut using an inner knife. This inner knife must be ensured sufficiently hot to hot. This aims to maintain the quality of plastic bottles. The less hot knife makes the bottle partly closed in the neck so that the bottle is clogged. Next the bottle which has been cut into the mat is pressed by the mat to form a pattern as requested and pressed by the bobbin to form a room in a plastic bottle. The pressure of the matras and the spool working together aims to prevent the bottle from separating the streaks aside from the connection of the bottle (bottle ear) or silting the volume of the bottle.
Table 1.

Percentage Data of Product Defects by Type

\begin{tabular}{ccccc}
\hline \hline No & $\begin{array}{c}\text { Type of Defective } \\
\text { Product }\end{array}$ & $\begin{array}{c}\text { Number } \\
\text { (pcs) }\end{array}$ & $\begin{array}{c}\text { Percentage of } \\
\text { disability (\%) }\end{array}$ & $\begin{array}{c}\text { Cumulative } \\
\text { percentage (\%) }\end{array}$ \\
\hline 1. & Dirty bottles & 49 & 28.16 & 28.16 \\
2. & Half dead end bottle & 52 & 29.89 & 58.05 \\
3. & Dent bottle & 73 & 41.95 & 100 \\
\hline & Total & 174 & 100 & \\
\hline \hline
\end{tabular}

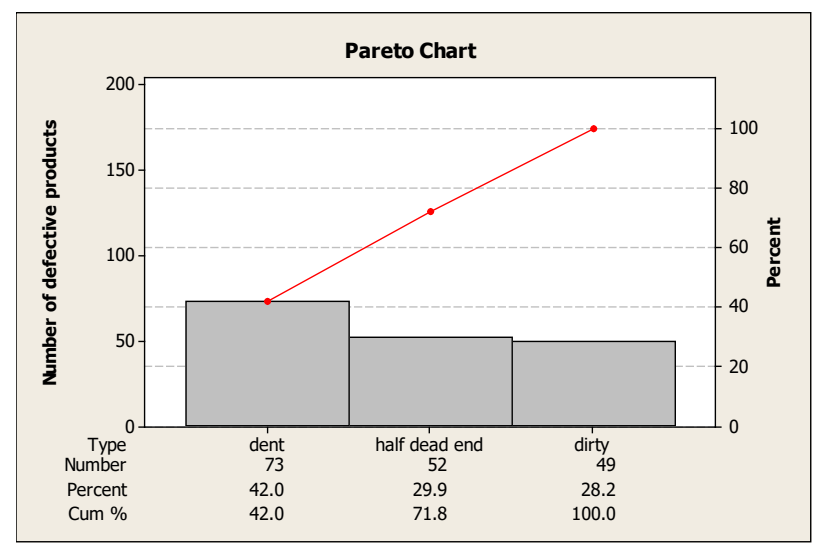

Figure 6. Pareto Diagram of a Plastic Bottle Defect Product.

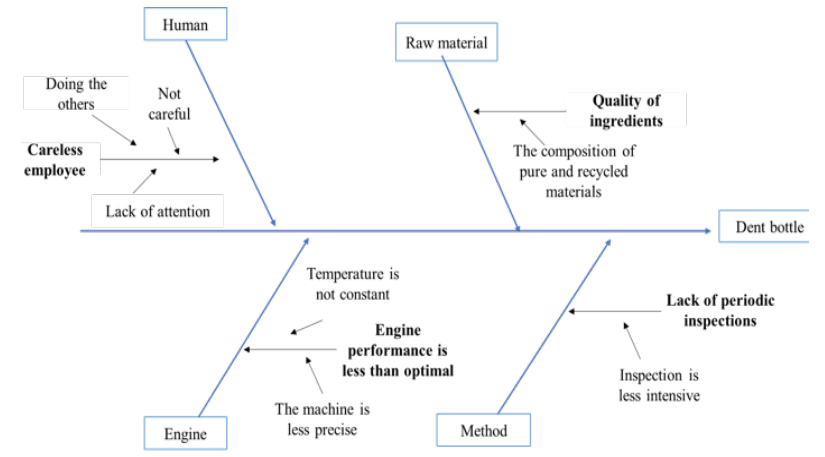

Figure 7. Diagram of causes and effects of dented plastic bottles

This process takes longer than the previous process, because when printing, on the outside of the mat there is a cooler in the form of water that is channeled from the hose to the engine matras. Hot plastic molds are formed on the mat and cooled on the matras to form a perfect plastic bottle and the output from this stage does not make the plastic bottles easily formed again by the next step. After the product is good, the production can take place and monitor the first 10 minutes, if there are more defective products, then an analysis can be made of the cause and then reset to the cause. After the process is complete, production continues until completion. Then the results of plastic bottles are not completely perfect, because there are still tails and heads that must be cut, this will be followed up on the sorting process. The sorting process not only cuts off the tail and head, but also checks the product produced whether there are defects or not. After the sorting process is finished then packing and finishing are done. As in the flow diagram of the production of plastic bottles above (figure 5)

\section{Pareto Diagram}

Pareto diagrams are used to analyze where the location of most product defects and cumulative product defects. Based 
The $1^{\text {st }}$ International Conference on Business and Engineering Management (IConBEM)

February $1^{\text {st }} 2020$, Institut Teknologi Sepuluh Nopember, Surabaya, Indonesia

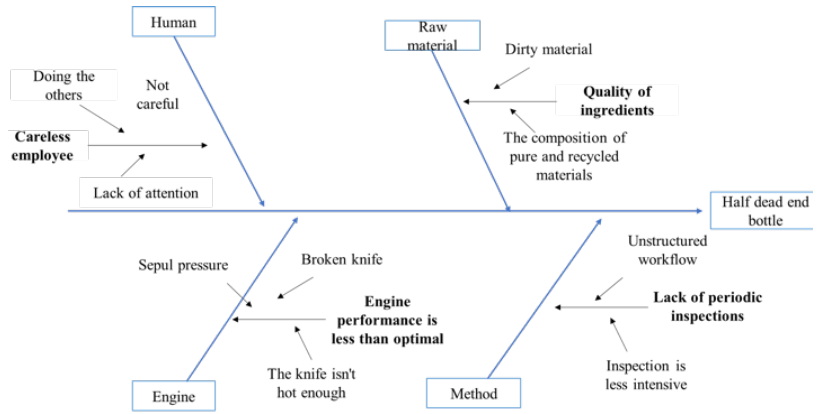

Figure 8. Cause and Effect Diagram of a Half Dead end Plastic Bottle.

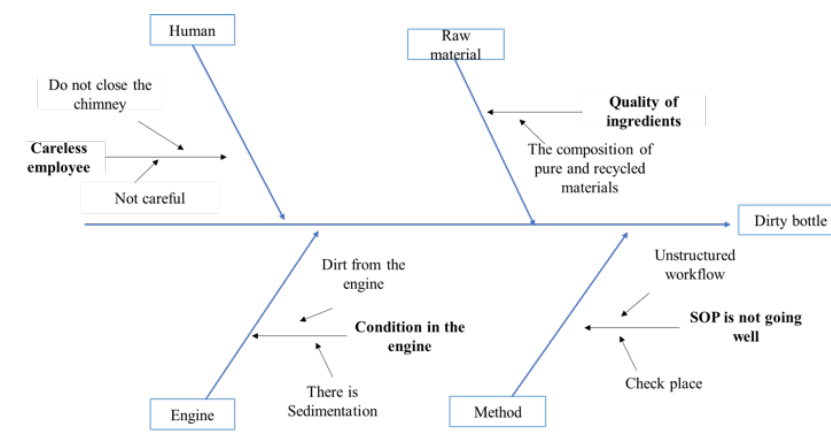

Figure 9. Cause and Effect Diagram of Dirty Plastic Bottles

on the data in Table 1, the number of defects in each type of defect is calculated. The following table shows the calculation of the number of defective products. In addition to the table above, here is a visualization of the Pareto diagram.

In Figure 6 shows that the most defective products produced during production are dented bottles with a percentage of $73 \%$, then half dead end bottles with a percentage of $52 \%$, and the least are dirty bottles with a percentage of $49 \%$. So it can be concluded that further action and analysis needs to be done for the production of dented plastic bottles. The following is the author's analysis with the results of interviews with direct interviewees about the causes of defects in plastic bottle products.

The cause of dented plastic bottles according to the diagram above (Figure 7), mostly caused by humans and machines. The machine used is indeed old and the precision of the machine needs to be monitored intensely, so employees must monitor at a certain time and follow up when it is seen to produce product defects.

The causes of dead-end plastic bottles based on the diagram above (Figure 8) are mostly caused by machines. A knife that is less hot and a pressure less sepul can cause a half dead end bottle. These causes can be reduced if the employee intensively monitors the results, the state of knife heat and pressure of sepul. The temperature flowing to the blade must be really hot, this keeps the mold cut neatly from scratching or covering the surface of the mold. Sepul pressure is also maintained so that the maximum pressure.

The main cause of dirty plastic bottles according to the diagram (see Figure 9) is caused by humans, machines, and methods. Machine chimney as the main place for inserting plastic pellets (raw material) and its place is above the machine and facing upwards. The condition of the production room is not closed so that dust and other impurities can easily

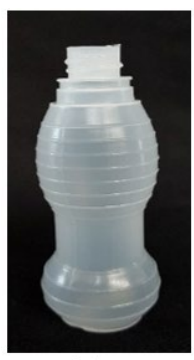

(a)

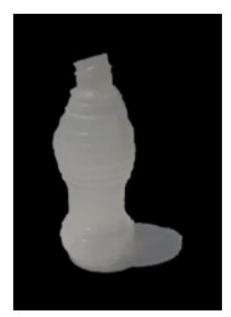

(e)

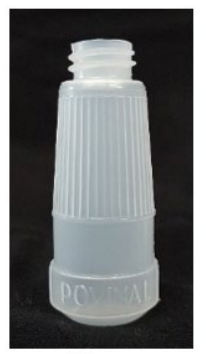

(b) (c)

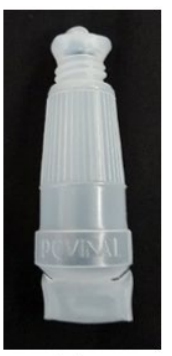

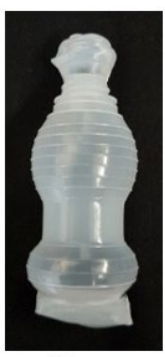

(d)

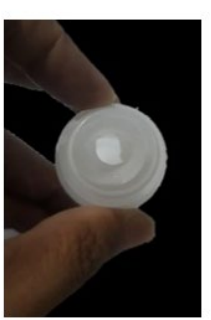

(f)

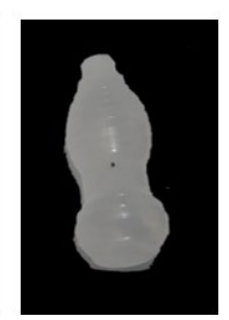

(g)
Figure 10. Production of Plastic Bottles for Glue (b \& c), for Ink ( $\&$ d), Dented Bottles (e), Half Dead end Bottles (f), and Dirty Bottles (g)

enter the engine chimney. After entering the raw material, the employee must close the engine chimney. But because it is considered trivial and has no major effect by employees so it is not closed again. In addition, employees also control and do everything else, so that the small things to close the chimney are ignored. In addition, it is also caused from raw materials. Raw material with recycled plastic seed mixture can cause dirty plastic bottles, it does not rule out the recycled plastic seeds the process is also mixed up with dust or other dirt or plastic seeds that have been recycled many times so that the elasticity and color of the material change and cause plastic bottles not only dirty, but also change color. The results of the production of plastic bottles are not all good, of course there are defects such as bottles that are half dead end, dirty, and dented. Here are some pictures of good and defective plastic bottles.

Figure 10. (a) and (b) are pictures of plastic bottles of good quality, (c) and (d) are bottles that have just finished production and have not yet been sorted, so the top and bottom have not been cut, (e) are dented bottles on the bottle cap, (f) is a half dead end bottle on the neck of the bottle, (g) is a dirty bottle.

\section{Scatterplot diagram}

Some product defects that have been obtained and analyzed based on flow charts, there is a possibility between product defects have a causal relationship. The pattern of relationships between correlations can be stated to have positive, negative, and unrelated relationships. Figure 11 show the correlation between the defects of plastic bottle product.

Figure 11 shows the relationship between the cause of dented bottles and half dead end bottles. This can be seen from the $\mathrm{x}$-axis and the $\mathrm{y}$-axis are interconnected even though there is a different point, but in general the picture is interconnected. Figure 11 shows the existence of a scatterplot negative pattern, this shows that the greater the cause of a half-dead bottle will result in smaller causes of dented bottles, 
The $1^{\text {st }}$ International Conference on Business and Engineering Management (IConBEM)

February $1^{\text {st }} 2020$, Institut Teknologi Sepuluh Nopember, Surabaya, Indonesia

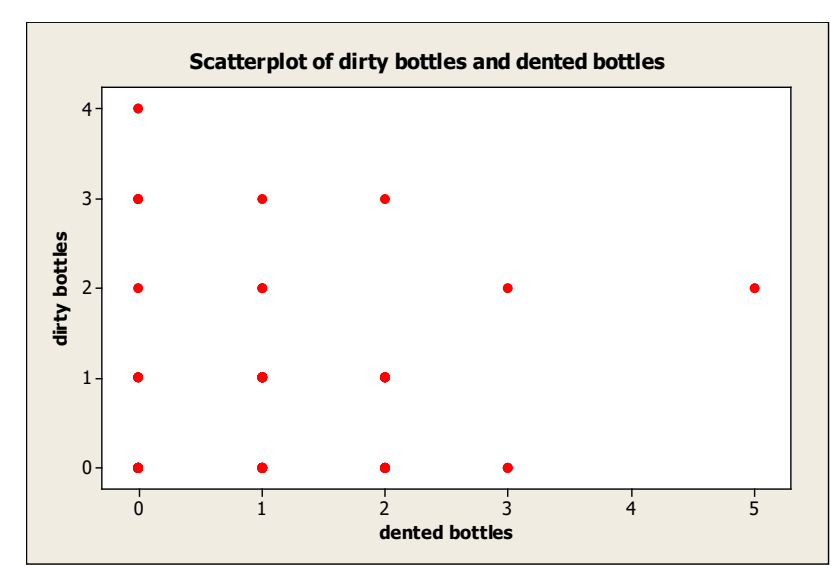

Figure 11. Scatterplot Of A Half Dead End Plastic Bottle Versus A Dented Plastic Bottle.

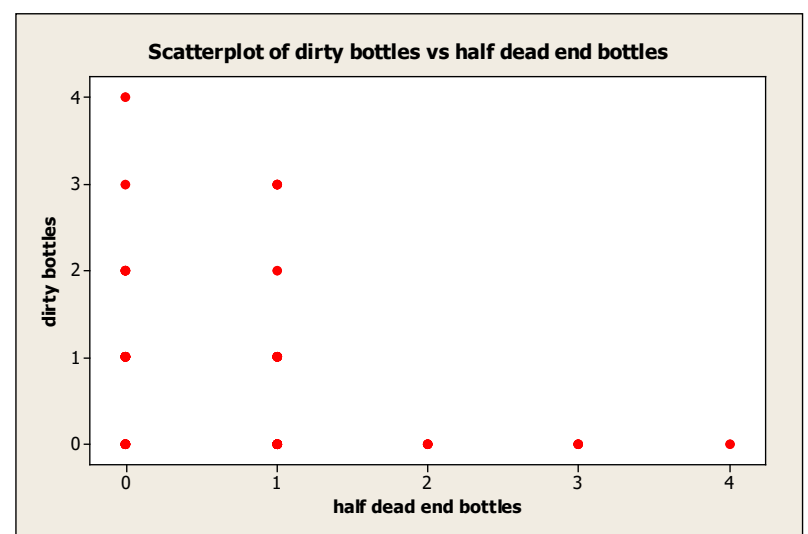

Figure 12. Scatterplot of A Dirty Plastic Bottle Versus A Half Dead end Plastic Bottle.

and the greater the cause of dented bottles, the smaller the cause of half dead end bottles. It can be concluded that the causes of dented and half dead end bottles have the opposite relationship. Based on the previous analysis on the flow chart, it shows that the half dead end bottle is caused by the heat of the knife and the dent bottle is caused by the heat of the engine. So the heat flow for the machine and knife comes from the same source, then the heat is branched and divided unevenly towards the blade and the machine, so it takes a while to make the heat evenly toward the blade and the machine.

Figure 12 shows the relationship between dirty bottles and half dead end bottles. This can be seen from the $\mathrm{x}$-axis and the $y$-axis are interconnected. Figure 12 shows the existence of a scatterplot negative pattern, this shows that the greater the cause of dirty bottles will result in the smaller causes of half dead end bottles, and the greater the cause of half dead end bottles, the smaller causes of dirty bottles. It can be concluded that the causes of dirty bottles and half dead end bottles have the opposite relationship. Based on the previous analysis in the flow chart, it shows that there is actually no relationship between the cause of a half dead end dirty bottle, because the cause of a dirty bottle is the presence of dust mixed in the raw material and the half dead end bottle comes from the heat of the knife.

Figure 13 shows that there is no relationship between the causes of dirty bottles and dent bottles. It can be seen that the plot points spread and do not form positive or negative

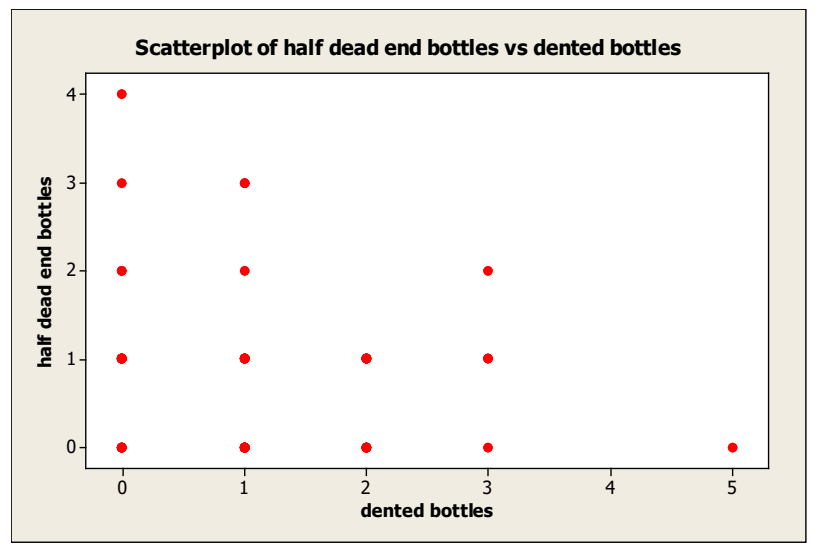

Figure 13. Scatterplot of Dirty Plastic Bottles Versus Dented Plastic Bottles.

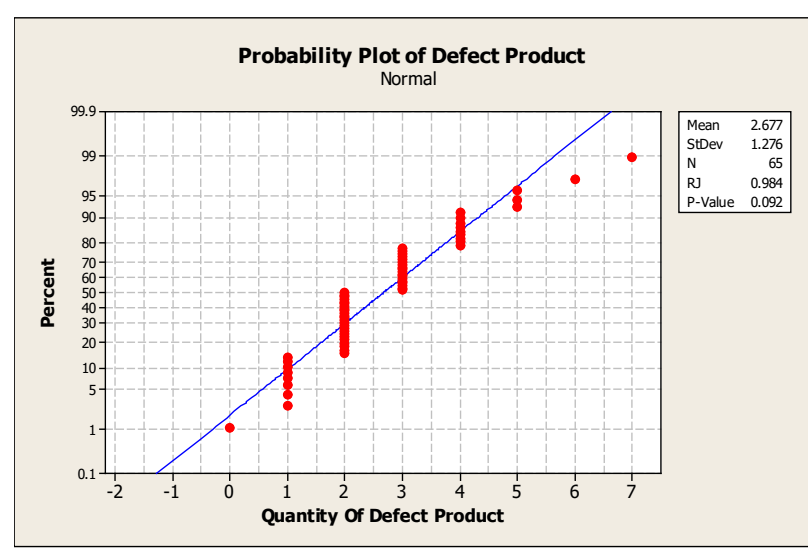

Figure 14. Ryan Joiner's Normality Test.

patterns. If analyzed from the flow chart above, it shows that the process of getting dirty defective products and dents are not interconnected. Dirty bottles are caused by careless employees who do not close the engine chimney (input) so that dirt dust is processed as raw material, and dented bottles are caused by engine temperatures that are too hot so the two causes are not interconnected to get defective products.

The next step is processing data using a control chart. Before processing the data using the control chart, the data normality test is performed first to ensure the data is normally distributed or not. Normal data will affect how the next data is processed. Here are the results of data processing using Minitab to find out the data obtained are normally distributed or not. If the data is not normal, then the data must be processed first to normalize the data. Normality test results are listed as in Figure 14.

The picture (Figure 14) shows the p-value of 0.092 . According to statistics, if p-value is more than alpha, where alpha is 0.05 , then the data can be said to be normally distributed. However, if the p-value is less than alpha, it can be said that the data is not normally distributed. In Figure 14. shows the p-Value is more than alpha, so it can be concluded that the data has normal distribution. Then the data is processed using a control chart.

Figure 15 is the distribution of the proportion of defective products. From this figure, it can be seen that there is one data that causes the map to be uncontrollable, because it is out of control. One point shows the number one, based on the Minitab test the data is out of control because of a point or more than 3 sigma from the center of the center line. The map 


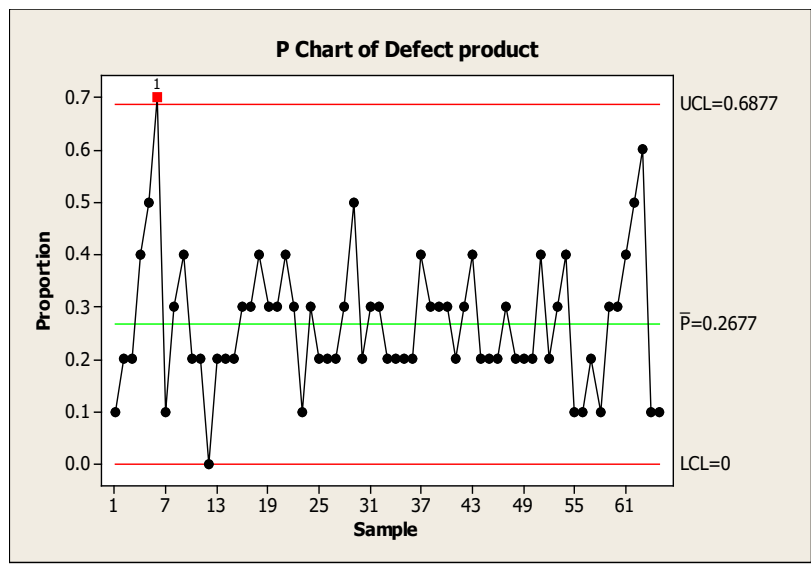

Figure 15. Map of P Data Defect Product (Uncontrolled).

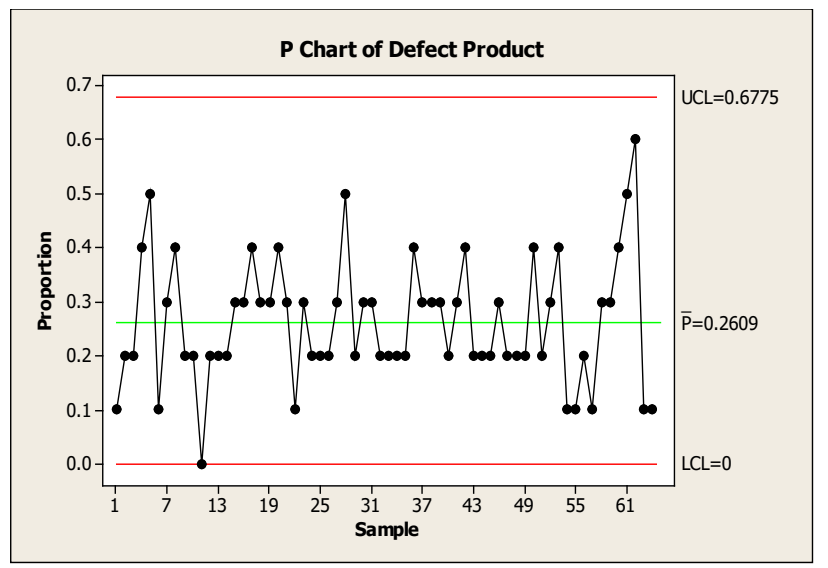

Figure 16. Map of P Data Defect Product (Controlled).

Table 2.

Analysis of FMEA In The Plastic Bottle Home Industry

\begin{tabular}{|c|c|c|c|c|c|c|c|}
\hline Factor & Due to process failure & $\mathbf{S}$ & Cause of failure & $\mathbf{O}$ & Control carried out & D & RPN \\
\hline \multirow[t]{3}{*}{ Human } & Presence of defective products & 2 & Not careful & 4 & $\begin{array}{l}\text { Operators are given a reprimand and given } \\
\text { directions }\end{array}$ & 1 & 8 \\
\hline & & & Careless employee & 5 & Operators are monitored and given direction & 2 & 10 \\
\hline & There was a work accident & 2 & Incautious & 1 & Operators are given gloves & 1 & 2 \\
\hline Machine & $\begin{array}{l}\text { The production process is } \\
\text { interrupted }\end{array}$ & 4 & $\begin{array}{l}\text { Engine performance is less than } \\
\text { optimal }\end{array}$ & 4 & Perform regular machine maintenance & 4 & 64 \\
\hline \multirow[t]{2}{*}{$\begin{array}{l}\text { Raw } \\
\text { material }\end{array}$} & A product defect has occurred & 3 & $\begin{array}{l}\text { There is a mixture of recycled } \\
\text { materials }\end{array}$ & 2 & Control the ingredients & 2 & 12 \\
\hline & & & The presence of dust dirt & 4 & Close the engine chimney & 2 & 24 \\
\hline \multirow[t]{2}{*}{ Method } & A product defect has occurred & 2 & Inspection is less intense & 3 & Given explanations and insights & 2 & 12 \\
\hline & & & The workflow is less structured & 2 & SOP is given clearly and in detail & 2 & 8 \\
\hline
\end{tabular}

is out of control because it is influenced by external factors that can be traced (assignable causes) such as material, operators, and so forth. To analyze the specific causes of this problem, it will be discussed using a causal diagram and FMEA analysis. Furthermore, making the map controllable can be done by deleting one data which causes uncontrollable.

Figure 16 shows that the proportion of product defects has reached the control limit so that it can be said that the data is in a controlled state and can be further analyzed. From the above data, the UCL value is 0.6775 , the average defect product is 0.2609 , and the lower limit is 0 . To maintain product quality, this home industry sets a maximum defect limit of $10 \%$. This figure is determined based on manual workmanship and machine conditions that are no longer prime. While the average result of the proportion of product defects obtained is $26 \%$ so that the home industry is doing additional work to check the final product before packaging. The magnitude of the product defects and how to overcome them will be further analyzed in the next section.

Based on the previous analysis, there are various causes of plastic bottles that are half dead end, dirty, and dented. The following is an FMEA analysis of the plastic bottle home industry based on the author's analysis, interviews with informants and employees.

Based on Table 2, the highest severity value is 4 in the engine factor. In this case, the machine has the biggest impact in influencing production output. Most product defects are caused by machines that are less stable in operation. The engine temperature and pressure of the mattress and unstable pressure make the dent bottle or half-dead bottle. Occurrence is an assessment of the probability of producing a product defect. Based on Table 3, the highest occurrence value is 5 in the human factor. This is due to human carelessness that cannot be eliminated, thus making the product defect bigger and more. Employees are not only careless in terms of raw materials, but also in machine sets. Because this makes the engine performance is also disrupted, now the product defect is increased to three, namely dented bottles, dead-end bottles, and dirty bottles. Detection is the ability to control the occurrence of failures. Table 2, the highest detection value is 4 on the engine factor. The engine factor is quite difficult to detect product defects, this is due to the machine not having a notification if the product is defective.

RPN values and RPN ranks can be seen in Table 3. Based on the table, the highest RPN values are machine factor, then raw materials, methods, and finally method. The machine has a very big influence on the defect of the product produced, because the machine is a product maker. If the temperature is not too hot or the machine does not run according to the control, it will produce a product that is not appropriate, causing product defects. In addition to machinery, raw materials are also quite influential on product defects. Dirty raw materials or recycled raw materials make the quality of 
The $1^{\text {st }}$ International Conference on Business and Engineering Management (IConBEM)

February $1^{\text {st }} 2020$, Institut Teknologi Sepuluh Nopember, Surabaya, Indonesia

Table 3.

Results of RPN scores

\begin{tabular}{ccccc}
\hline \hline Factor & Due to process failure & RPN & Number of RPN & Rank \\
\hline Human & Presence of defective products & 28 & 30 & 3 \\
& There was a work accident & 2 & 64 & 1 \\
Machine & The production process is interrupted & 64 & 36 & 2 \\
Raw material & A product defect has occurred & 36 & 20 & 4 \\
Method & A product defect has occurred & 20 & & \\
\hline \hline
\end{tabular}

the product decreases. Bottles with dirty conditions will make the bottle look un-aesthetic and show the performance of an unprofessional home industry. Bottles with too many recycled raw materials can reduce the quality of bottles, as can make bottles leak easily. This is due to decreased bottle resistance, elasticity and decreased bottle resistance. The existence of humans helps reduce the defect level of the product produced, because it can control.

However, humans are not completely thorough so they have not completely reduced the product defect and can also increase the cause of the product defect. Furthermore, namely the work method, actually the work method has been done correctly, but when there is a problem with the machine, the employee does not check the origin of the cause of the machine, so the inspection is not regular and tends to repeat activities that can take time. Failures that occur on the machine not only produce product defects, but also loss of cost and time. The intended cost loss is the waste of raw material costs, electricity costs, employee costs, and so forth. Whereas the intended time loss is that it should have finished sooner but now it can be slower. Based on the level of RPN above, companies can take appropriate actions based on RPN ranking.

The proposed improvements to the home industry of plastic bottles based on the results of FMEA and analysis of seven tools namely:

1. The need for intense engine maintenance, because engine maintenance has been going on for quite a long time, about 15 to 20 years, or even when the machine is damaged.

2. There is a need for training and employee learning of the machine to keep the machine in top condition. Employees must also learn basic and core causes that result in machine instability. In addition, the home industry must make clear SOP rules about machine operations.

3. Home industry should provide insight and knowledge for other employees regarding machine operations. It aims to not depend on just one person.

4. Home industry should archive data both about defective products, good products produced, products sent, date sent, and other data archives, in order to clarify incoming data, data out, and other data that may be needed at any time.

5. Home industry should provide direction and strict sanctions for employees who are very careless.

6. If opening the lid of the engine chimney is a waste of time, you should make a partition or cover that is safe enough so that the raw material does not get dirty easily.

\section{REFERENCES}

[1] Khomah and E. Siti Rahayu, "Aplikasi Peta Kendali p sebagai Pengendalian Kualitas Karet di PTPN IX Batujamus/Kerjoarum," Agrar. J. Agribus. Rural Dev. Res., vol. 1, no. 1, pp. 12-24, 2015.

[2] M. S. Hidayatullah Elmas, "Pengendalian Kualitas Dengan Menggunakan Metode Statistical Quality Control (Sqc) Untuk Meminimumkan Produk Gagal Pada Toko Roti Barokah Bakery," Wiga J. Penelit. Ilmu Ekon., vol. 7, no. 1, pp. 15-22, 2017.

[3] N. B. Puspitasari and A. Martanto, "Penggunaan Fmea Dalam Mengidentifikasi Resiko Kegagalan Proses Produksi Sarung Atm (Alat Tenun Mesin) (Studi Kasus Pt. Asaputex Jaya Tegal)," J@Ti Undip J. Tek. Ind., vol. 9, no. 2, pp. 93-98, 2014.

[4] Andriyani and R. Rumita, "Analisis Upaya Pengendalian Kualitas Kain Dengan Metode Failure Mode and Effect Analysis (Fmea) Pada Mesin Shuttel Proses Weaving PT Tiga Manunggal Synthetic Industries," J. Tek. Ind. Fak. Tek. Univ. Diponegoro, 2015.

[5] K. Philip, Marketing Management, 14 Edition. Pearson, 2012.

[6] G. David, Managing Quality "The Strategic and Competitive Edge." New York, London: The Free Press, 1988.

[7] S. Dutta, M. B. Nadaf, and J. N. Mandal, "An Overview on the Use of Waste Plastic Bottles and Fly Ash in Civil Engineering Applications," Procedia Environ. Sci., vol. 35, pp. 681-691, 2016.

[8] N. Fadlalla, "A cknow ledgem ent," 2010.

[9] J. Hopewell, R. Dvorak, and E. Kosior, "Plastics recycling: Challenges and opportunities," Philos. Trans. R. Soc. B Biol. Sci., vol. 364, no. 1526, pp. 2115-2126, 2009.

[10] Iacovidou, A. P. M. Velenturf, and P. Purnell, "Quality of resources: A typology for supporting transitions towards resource efficiency using the single-use plastic bottle as an example," Sci. Total Environ., vol. 647, pp. 441-448, 2019.

[11] B. Briasco, P. Capra, A. C. Cozzi, B. Mannucci, and P. Perugini, "Packaging evaluation approach to improve cosmetic product safety," Cosmetics, vol. 3, no. 3, 2016.

[12] Al Fakhri, "Pengaruh Kualitas Terhadap Keputusan Pembelian," 2010.

[13] R. B. Chase and E. R. Jacob, "2006 Book Chase _Operations Management for competitive advantage.pdf." pp. 318-371, 2006. 